\title{
Conceptualizing Cold Disasters Disaster Risk Governance at the Arctic Edge
}

Lauta, Kristian Cedervall; Vendelø, Morten Thanning; Sørensen, Birgitte Refslund; Dahlberg, Rasmus

\author{
Document Version \\ Accepted author manuscript
}

Published in:

International Journal of Disaster Risk Reduction

DOI:

10.1016/j.ijdrr.2017.12.011

Publication date:

2018

\section{License \\ CC BY-NC-ND}

Citation for published version (APA):

Lauta, K. C., Vendelø, M. T., Sørensen, B. R., \& Dahlberg, R. (2018). Conceptualizing Cold Disasters: Disaster Risk Governance at the Arctic Edge. International Journal of Disaster Risk Reduction, 31, 1276-1282.

https://doi.org/10.1016/j.ijdrr.2017.12.011

Link to publication in CBS Research Portal

\section{General rights}

Copyright and moral rights for the publications made accessible in the public portal are retained by the authors and/or other copyright owners and it is a condition of accessing publications that users recognise and abide by the legal requirements associated with these rights.

Take down policy

If you believe that this document breaches copyright please contact us (research.lib@cbs.dk) providing details, and we will remove access to the work immediately and investigate your claim. 


\title{
Conceptualizing Cold Disasters: Disaster Risk Governance at the Arctic Edge
}

\section{Kristian Cedervall Lauta, Morten Thanning Vendelø, Birgitte Refslund Sorensen, Rasmus Dahlberg}

\author{
Journal article (Accepted manuscript*)
}

\section{Please cite this article as:}

Lauta, K. C., Vendelø, M. T., Sarensen, B. R., \& Dahlberg, R. (2018). Conceptualizing Cold Disasters: Disaster Risk Governance at the Arctic Edge. International Journal of Disaster Risk Reduction, 31, 1276-1282. DOI: 10.1016/j.jijdrr.2017.12.011

DOl: 10.1016/j.ijdrr.2017.12.011

* This version of the article has been accepted for publication and undergone full peer review but has not been through the copyediting, typesetting, pagination and proofreading process, which may lead to differences between this version and the publisher's final version AKA Version of Record. 


\title{
Conceptualizing Cold Disasters: \\ Disaster Risk Governance at the Arctic Edge
}

\author{
Kristian Cedervall Lauta \\ University of Copenhagen \\ Faculty of Law \\ Centre for Institutional Law, Conflict and Crisis \\ Karen Blixens Plads 16 \\ DK-2300 Copenhagen S \\ Email:kristian.lauta@jur.ku.dk \\ Morten Thanning Vendel $\varnothing$ \\ Copenhagen Business School \\ Department of Organization \\ Kilevej 4A \\ DK-2000 Frederiksberg \\ Email:mtv.ioa@cbs.dk \\ Birgitte Refslund Sørensen \\ University of Copenhagen \\ Department of Anthropology \\ Øster Farimagsgade 5 \\ DK-1353 Copenhagen K
}

Email: birgitte.soerensen@anthro.ku.dk

$\&$

Rasmus Dahlberg

Royal Danish Defence College

Institute for Military History and War Studies

Ryvangs Allé 1

DK-2100 Copenhagen $\varnothing$

Email: rada@fak.dk

Accepted for publication in International Journal of Disaster Risk Reduction, special issue on Nordic Models for Coping with Disaster 


\title{
Conceptualizing Cold Disasters: \\ Disaster Risk Governance at the Arctic Edge
}

\begin{abstract}
Present literature on disasters predominantly focuses on warm, accessible and well-populated contexts. However, as human activities in Arctic and Antarctica become more common, cold contexts, and their special characteristics, become more relevant to study. In the present article, we explore in more depth the particular circumstances and characteristics of governing what we call 'cold disasters'. The article is structured in four overall parts. The first part, Cold Context, provides an overview of the specific conditions in a cold context, exemplified by the Arctic, and zooming in on Greenland to provide more specific background for the paper. The second part, Disasters in Cold Contexts, discusses 'cold disasters' in relation to disaster theory, in order to, elucidate how cold disasters challenge existing understandings of disasters, also it provides examples of emergency scenarios, in order to, demonstrate the demanding dynamics of cold contexts. In the third part, Governing Cold Disasters, we discuss the main implications for the governance of 'cold disasters' in the Greenlandic context. Finally, we offer our conclusions.
\end{abstract}

\section{Introduction}

The literature on disasters predominantly focuses on warm, heavily-populated and relatable climates. However, as human activities in the Arctic and Antarctica become more common, more attention must be paid to disasters in cold contexts, and their special characteristics. In particular, because cold disasters and their consequences differ rather distinctly from warm disasters on at least three dimensions. First, cold disasters unfold in natural environments where, due to low temperatures and extreme weather, humans can die much faster when they encounter a disaster, and this sets new standards for the speed by which emergency relief must be provided. Second, for most humans, cold contexts represent unlivable habitats, and thus, it is common for cold disasters to unfold in sparsely populated spaces, with limited physical and social infrastructure ${ }^{1}$, including limited capacity for rescuing and protection. Third, cold disasters commonly involve complex institutional set-ups and sometimes even contested jurisdictions, for example, in the form of ambiguities regarding the mandates, obligations and limitations of countries and authorities, and these ambiguities must often be resolved while cold disasters unfold. Each of the three dimensions might by themselves produce complex challenges for the gover-

\footnotetext{
${ }^{1}$ Zakour \& Gillespie [1] refer to these two entities as the physical environment, including the natural, built and technological environments, and the social environment, including the economic, political and cultural environments.
} 
nance $^{2}$ of cold disasters, yet, when combined they become truly cumbersome to govern, and difficult to address by use of traditional conceptualizations and models of disaster governance. As an example, consider the following incident.

In the evening on Saturday the June 17th, 2017 a tsunami struck the small settlement of Nuugaatsiaq, located $100 \mathrm{~km}$ from the nearest town Uummanaq, on the west coast of Greenland. The wave was caused by an earthquake measuring 4,0 on the Richter scale - a relatively small seismic event in itself, but the quake triggered a major landslide, and a piece of rock and gravel of approximately 1,100 x 300 meters slid into the Karat Fjord. This mass movement created a tsunami, which travelled about 30 kilometers into the fjord before it reached the shores of Nuugaatsiaq. Here, the ice-cold water rapidly flooded the settlement, washed away 11 buildings, and damaged the power station. Despite a total of 101 people being registered as residents in Nuugaatsiaq, in the immediate aftermath of the tsunami the police could only account for 78 . Three days later, the police concluded that the tsunami had probably taken the lives of three adults and a child, who had been inside one of the houses that were washed out to sea. Weeks later, the inhabitants remained evacuated due to the risk of more landslides and tsunamis.

The Nuugaatsiaq tsunami shows how a small geophysical event is extrapolated into a disaster by the factors inherent in the cold context. The population was extremely vulnerable, due to the cold; help could not arrive before many hours after the incident, due to the lack of infrastructure; and the assistance included a multiplicity of actors, including the Royal Danish Navy and the Danish Emergency Management Agency, due to overlapping jurisdictions.

In the coming years, we are likely to face an increase of such cold disasters. These may be caused directly by natural phenomena, for example, icebergs, mass movements, earthquakes, volcanoes, landslides and dangerous wild life, or by changing economic, political and social activities, for example, commercial shipping, tourism, off- and onshore natural resource exploitation $[3,4,5]$. This proliferating situation generates new challenges not only for people living in cold contexts, but also for disaster risk managers and disaster research scholars, whose organizational and conceptual tools are largely developed on the basis of disasters in significantly different contexts.

In the present article, we explore in more depth the particular circumstances and characteristics of governing ${ }^{3}$ what we call 'cold disasters', and thereby, the paper sets out to investigate how disasters in cold contexts distinguish themselves from other disasters, and what the implications hereof are for the

\footnotetext{
${ }^{2}$ Alexander [2] argues that governance is one of the principal keys to disaster risk reduction, and emphasizes that "it requires strong, responsive institutions, social participation and sensitivity to the other issues inherent in disaster vulnerability".

${ }^{3}$ Governance in this article should be understood in accordance with the definition put forward by Political Scientist Mark Bevir, as "all processes of governing, whether undertaken by a government, market, or network; whether over a family, tribe, corporation, or territory; and whether by laws, norms, power, or language" [7].
} 
conceptualization and governance of cold disasters. Hence, the paper can also be viewed as a response to Alexander's [6] recent call for new theory in the field of disaster risk reduction.

The article is structured in to four parts with overarching themes. The first part, Cold Context, provides an overview of the specific conditions in a cold context, exemplified by the Arctic, and hones in on Greenland to provide more specific background for the paper. The second part, Disasters in Cold Contexts, discusses "cold disasters" in relation to disaster theory, in order to, elucidate how cold disasters challenge existing understandings of disasters. The section also provides examples of emergency scenarios, in order to, demonstrate the demanding dynamics of cold contexts. In the third part, Governing Cold Disasters, we discuss the main implications for the governance of "cold disasters" in Greenlandic context. Finally, in the fourth part we offer our conclusions.

It is important to note that this article predominantly focuses on the case of Greenland. We acknowledge that by doing so we can in no way comprehensively address all the issues involved in managing disasters in complex cold contexts. We highlight Greenland as a concrete example that will inevitably highlight different kinds of issues than if we analyzed say Nunavut, Svalbard or Siberia. However, we apply this case as a general example of the challenges that all Arctic communities face. Meanwhile, fully acknowledging the potential limitations and blindsides of such an approach.

\section{A Cold Context - the Arctic}

Located above the Northern Polar Circle and covering roughly $11 \%$ of the planet's surface, the Arctic constitutes a cold context, and epitomizes a series of extreme challenges for human life. It is a desolate and harsh landscape that may be rewarding in its purity and beauty, but unforgiving when it comes to emergencies.

The Arctic is characterized by extreme and rapidly changing weather that presents significant challenges to human activities. Most of its landmass is located in the Arctic climate zone, which has an average temperature of less than 10 degrees Celsius during the hottest month of the year, and winter temperatures as low as minus 50 degrees Celsius [8]. And even if much sea ice disappears from the Arctic waters during the summer and the water temperature rises, it does not exceed 3-4 degrees Celsius. The Arctic constitutes a vast area with considerable variation in weather, for example, in Greenland, where the inland ice and ocean currents create considerable regional variation in temperature and humidity, and causes rapidly changing weather with heavy storms and shifting visibility. Due to the harsh weather conditions in Greenland, domestic flights, are often delayed or cancelled, and thus, spending an extra day or two in an airport when flying into and out of Greenland is not uncommon. Similarly, the unforeseeable weather creates troublesome conditions at sea.

A second characteristic of cold contexts is the extraordinary sprawl and sparsely populated spaces. The Arctic consists of approximately 18 million square kilometers sea and 8 million square kilometers land. As an illustration the distance from the northern part of Greenland to the southern part exceeds the distance from Oslo in Norway to Tunis, the capital of Tunisia in North Africa. The enormous di- 
stances in the Arctic in turn makes searching for a ship in distress or a downed plane, not to speak of rescuing people trapped in remote locations, an extremely challenging task both in terms of locating, accessing and returning safely from the emergency site, with bad weather potentially further complicating and delaying response efforts. The Arctic has a population of only 4 million people, of which more than two thirds live in urban areas and the remaining in smaller towns and settlements [9]. In Greenland, which covers an area almost four times bigger than France, 31,5\% of the 55,860 inhabitants live in the capital Nuuk; approximately half the population lives in 12 towns with more than 1,000 people, and the other half lives in smaller, scattered settlements [10,11]. As a consequence, elaborate physical and social infrastructures do not exist in Greenland, for instance there are no railways and only 150 kilometers of roads - of which less than half are paved, and only two settlements, Ivittuut and Kangilinnguit in the South, are connected by road. During the winter, the Greenlanders transport themselves by dog sleighs and snowmobiles, and during the summer much travel is conducted by sea, and many Greenlanders own small boats, which they use for local transport, fishing and hunting. Royal Arctic Line, the national carrier for passengers and cargo, services 13 major ports, of which only half are accessible all year round. In addition, there are approximately 200 smaller harbors, pontoons and quays, and remote areas can only be serviced using barges or smaller boats to unload cargo.

Air is another important means of transportation in the Arctic. Air Greenland, the national Greenlandic carrier, operates a diverse fleet of planes and helicopters, because of the challenges involved in servicing remote locations. 18 airfields are located close to populated areas of Greenland, whereas other locations are only accessible by helipad, and only two airfields, Kangerlussuaq and Narsasuaq (both former US airbases), can accommodate long-haul planes, and thereby, serve as gateways to the world, whereas the runway in the capital Nuuk is too short to accommodate such planes. The limited physical and social infrastructures have important implications for disaster management in the Arctic. In an emergency situation, the nearest equipment and assistance (helicopters, medical crew, floating barriers, etc.) are often located at least some thousand kilometers away. In some situations, it might be possible to get a helicopter to the scene of an accident, but when the helicopter gets there it is likely to be out of fuel, with no fuel immediately available, rendering the helicopter unable to sustain its operation. All Greenlandic territory is covered by one dedicated land-based Search and Rescue (SAR) helicopter $^{4}$, stationed in the southwest, and two to four Danish inspection ships and vessels patrolling the waters around the island - not all of them carrying helicopters. Thus, first responders may need several days to locate and get to the scene of an accident, and by then it may very well be too late [12].

Adding to the desolate and rough context outlined above, the Arctic is embedded in a complex institutional and political landscape perpetually in flux. It is an active battleground for a number of geopolitical struggles over commercial and military-strategic interests among its constituent nations (the

\footnotetext{
${ }^{4}$ Smaller helicopter can be released from other duties in case of emergency.
} 
USA, Canada, Finland, Greenland, Denmark, Norway, Iceland, Sweden and Russia) and others, like China, with an interest in the region [see, e.g., 13, 14]. While these global power struggles might not directly affect disaster management efforts, they do influence the overall stability of the political climate, which is necessary when addressing issues of emergency relief and disaster management. For instance, when making decisions on what to allocate resources for within the Arctic, security might supersede safety, due to the region's strategic location $[15,16]$ In the case of Greenland, the unique institutional arrangements also surface with regard to responsibility for disaster management and disaster risk reduction. The police in Greenland is Danish and operate similarly to other police districts in Denmark, while fire/rescue services are under Greenlandic municipal control. It is in turn the police's responsibility to direct all disaster operations under Greenlandic jurisdiction. However, for SAR operations, the police are solely responsible for operations within the baseline, connecting the outer shoals and islands, while the Danish Defense is responsible for events outside the baseline. Similarly, the Government of Greenland is responsible for managing cases of marine pollution less than three nautical miles of the coast, while Denmark is responsible for responding to anything beyond this point. A combination of these facts, and a restriction on Denmark's title to Eastern Greenland laid down by the International Court of Justice, ${ }^{5}$ means that Denmark maintains a relatively strong military presence in Greenland. ${ }^{6}$ Such a complex institutional landscape makes close and continuous cooperation between the Danish Defense, the police and various Greenlandic authorities necessary for any successful operation, almost independently of the scale and location of an incident. Differing interpretations of statutes and mandates, alongside cross-jurisdictional interactions are consequently an inevitable part of almost any disaster response operation in Greenland.

In the case of Svalbard, the emergence of the institutional and political landscape pursues a differrent trajectory emblematic to the Arctic context. Since its discovery in 1596, Dutch, Russian, Swedish, Basque, British, Danish, French, German, and Norwegian whalers, fishers, merchants, and miners have shown great interest in controlling the islands, which only became part of the Kingdom of Norway in 1920 with the signing of the Svalbard Treaty. However, the Treaty, which recognized Norwegian sovereignty and established Svalbard as a demilitarized, free economic zone, did not put an end to other nations' interest in the islands. For instance, during the Second World War both Germany and USSR established military presence on Svalbard and up until today, Russian commercial activities continue on Svalbard, in particular in the form of mining and oil exploration. This, obviously, led to several cold war disputes about infrastructure planning, for example, in 1951 and 1960 the USSR rejected Norwegian plans for the construction of a civil airport on the islands [17]. Hence, while colonial and post-colonial [19] pursuits have largely shaped the institutional and political landscape of Green-

\footnotetext{
5 Norway v. Denmark from 1993, http://www.icicij.org/docket/index.php?sum=401\&p1=3\&p2=3\&case=78\&p3=5

${ }^{6}$ A policy (on the one hand granted self-government and on the other strengthening the military presence) which some consider ambiguous, see for example Østerrud \& Hønneland [18].
} 
land, it is commercial interests that have formed the distinct area of Svalbard, and possibly Alaska. This however, does not make the institutional context more settled or less complex.

When combined with extreme and rapidly changing weather long distances and sparsely populated spaces; the limited physical and social infrastructures and complex institutional landscape create a challenging environment for the governance of disasters. As an example, consider the following imagined scenario. In 2011, Costa Deliziosa, a cruise ship not too dissimilar from the Costa Concordia, travelled to Illulissat in Greenland, zigzagging between icebergs in the fjord. Imagine a disaster playing out in the Disco Bay on the west coast of Greenland rather than near Isola del Giglio in Italy. The Arctic landscapes would have made such a disaster worse than the Costa Concordia's in at least four ways. It would have happened in a cold context, including very cold water, a higher risk of extreme weather, and a much shorter response window making any rescue mission tremendously more difficult. There would have been very limited pre-existing infrastructure available for the needed largescale SAR operation. Accordingly, besides the difficulty of reaching potential survivors, the rescue mission would have faced significant problems in getting them to safety. Local populations would be scattered, and have no pre-existing experience with SAR operations remotely similar to the scale and speed needed to save the passengers of Costa Deliziosa. Local responders would speak mainly Greenlandic or possibly Danish, which would be of little value for an international cruise ship. Finally, a successful response would depend on the authorities' ability to agree across institutions and mandates about whom should take charge of the response, and their ability to mobilize additional resources from other Arctic nations, in this case Canada and Iceland.

Arctic governance scholar Oren Young argues that the extent to which governance systems are designed with the principal features of the relevant biophysical and socioeconomic systems in mind, is a major determinant of their effectiveness [20]. Therefore in this context, extreme and rapidly changing weather, huge distances, small and geographically scattered populations, limited physical and social infrastructures, and complex institutional and political landscapes are factors that work simultaneously together and against one another when generating the assemblage we call "cold disasters", in turn influencing the ways in which such are handled.

In sum, we have illustrated in this section that the Arctic shares certain climatic and political features that are generalizable and distinguishes it in important ways from other parts of the world; yet there are vast differences within the region that inevitably shape disasters and disaster management as localized events. The extent to which these particular conditions are reflected in current disaster theory is our focus of the next section.

\section{Disasters in Cold Contexts: A Case for "Cold Disasters"}

Contemporary disaster theory generally perceives disasters through the theoretical lens of vulnerability $[21,22]$, which concerns the potential loss or harm inherent in an individual or thing [23]. As a concept, vulnerability serves as a bridging idea, linking research on disasters across both disciplines and 
hazards [24]. The so-called Pressure And Release (PAR) model [25], for instance, views disasters as composed of three interrelated "progression levels" of vulnerability; root causes, dynamic pressures, and unsafe conditions. According to the PAR model, disasters not only result from natural events, but are "also the product of the social, political, and economic environment (as distinct from the natural environment) because of the way it structures the lives of different groups of people" [25, 26]. Hence, vulnerability theory guides disaster research scholars to focus on structural and interconnected social causes of disasters, for example, the distribution of power, structures and resources, and it enables the disclosure of the deep justice dimension of disasters. Thereby, the PAR model gives way for the formulation of social critique, directed at the distributional foundations of the society in question, and it prompts a recalibration of the societal infrastructure.

When considering the characteristics of cold contexts described above it should be obvious that these particular conditions call for far more attention to be paid to the role of nature. Cold disasters, like the tsunami in Nuugaatsiaq, are at the same time both similar to disasters elsewhere and very different from these. The disaster took place in the intersection between pre-existing social vulnerability and a natural hazard, but it appears that the particular context, which embeds this intersection multiplied the effects of both. Yet, when applying the PAR-model to a cold context, disaster research scholars are led easily to look for structural causes of vulnerability, however we argue that in the case of the tsunami in Nuugaatsiaq, the main problem was the lack of social structures rather than distributive issues within these structures. As a consequence, it makes good sense to claim that vulnerabilities in a cold context are brought on by the absence of or distance to physical and social infrastructures, rather than complex interactions of these [27]. Therefore, the kind of vulnerability contributing to cold disasters is not directly comparable with the kind contributing to modern urban, infrastructural crises. Alongside this, the extreme absence of a clear and centralized political system, and the contentiousness of the land mass by several colonial entities that has come to define the Arctic as a continent, exacerbates further the ability to relive the vulnerability faced in cold disasters. In sum, the vulnerability theory, dominating contemporary disaster research, may explain why people in the Arctic are at risk, but it does not help us formulate good strategies in a context where further infrastructural investments and political stability are a pipe dream, and the wish for structural all-encompassing solutions are farfetched.

The hazards triggering cold disasters thus might not in themselves be complex, but, due to the limited physical, political and social infrastructures, emergency responders must do with what they have at hand, and do so within a highly constrained timeframe, and thus, simple problems easily become complex to address. In Nuugaatsiaq, the earthquake or even the unfortunate combination of hazards had hardly been a disastrous cocktail in other communities, but due to the harsh natural environment and the lack of infrastructures it became a major response and relief operation.

Our claim is that when considering disaster risk reduction in cold contexts, focusing on physical and social infrastructures is neither a relevant nor a viable solution. Hence, rather than focusing on a 
disaster theory based on social infrastructures, other research fields might better contribute to understand the challenges of disaster response and prevention without infrastructure. Thus, instead of looking to theory emerging from Hurricane Katrina or the earthquake in Haiti, one could seek inspiration with space operations, like the ill-fated Apollo 13 mission [28, 29, 30] or rescue operations after mining accidents like the dramatic event in Copiapó, Chile, in 2010 [31]. Responding to, and preparing for, disasters in the Arctic are more similar to the lessons drawn from isolated, stand-alone operations playing out in remote and hostile environments.

\section{Governing Cold Disasters: Adaptation within Limited Resources}

There is no reason to doubt that comprehensive measures such as significant investments in infrastructure and equipment, would improve the disaster response framework in a cold context like the Arctic. However, it is just as clear that such investments are not possible, as they would take up a disproportionnately large amount of the available resources for the Arctic. In turn, when disaster response strategies cannot be based on such measures, and the time pressure is high due to an extreme natural environment, then responsiveness and agility becomes essential for disaster management [32, 33, 34]. Responsiveness and agility can be achieved through adaptation, but not any kind of adaptation will do. In the following section we outline three different forms of adaptation, which we argue are crucial when responding to cold disasters. We focus on the adaptation of responses, organization and regulation. Despite knowing well that other forms of adaption could be crucial, we believe that the aforementioned are all forms of adaptation that disaster managers can implement and structurally improve. Thus, for each of the three forms of adaptation we set out to identify the challenges that make them relevant in a cold context; provide illustrative empirical examples; theorize about the particular form of adaptation; and we indicate what might be done, in order to improve more effective adaptation in the future.

\subsection{Adaptation of Responses: Improvising}

In emergency situations time is essential, but in cold contexts this becomes ever more crucial as responses must be speedy to save lifes. In the Arctic, minutes determine the difference between life and death for the affected humans. Also, in cold contexts disaster responses are constrained by the available resources and capabilities, as it is typically impossible to get additional resources and capabilities to the site of the disaster in due time. Consequently, emergency responders must do with what they have at hand, which can be problematic when responding to the often unpredictable and complex cold disasters.

Complex problem solving within a constrained timeframe often calls for improvisation, which Moorman \& Miner [35] define as: “...the degree to which the composition and execution converge in time." Hence, although Ciborra [36] argues that "the effective improviser never seems to be worried by (a lack of) time; she just acts at the appropriate time", in reality it is the lack of time to solve com- 
plex problems that leads people to improvise [37]. Furthermore, although disasters and accidents can be and are planned for, they seldom happen as imagined, thus improvisation becomes a necessity when dealing with them $[38,39]$.

According to Moorman \& Miner [35], improvisation may involve both modest adaptations, and the abandonment of all existing plans and routines. This is no less the case in cold contexts. As an illustration, consider the emergency evolving from Sunday February $21^{\text {st }} 2016$ 10:32 pm when the Canadian trawler SAPUTI, while fishing in the Straits of Davis, collided with sea ice, got a leak, and began to take in water, which gave it a heavy imbalance. The trawler's bilge pumps could not keep up with ingress of seawater, and thus, after being alarmed the Joint Rescue Coordination Centre in Halifax, Canada deployed an aircraft, which dropped four more bilge pumps to the trawler, early Monday February $22^{\text {nd }}[40]$. Later that day, around $2 \mathrm{pm}$, the Danish naval inspection vessel KNUD RASMUSSEN reached the position of SAPUTI, and moved three rescue technicians to the trawler where they inspected the damage caused by the ice, and assessed if it was possible to repair the leak in the trawler. At this point in time all the bilge pumps onboard had ceased to function, due to damages caused by intake of fish, and thus, hazard equipment and a new batch of bilge pumps were moved to SAPUTI. Both weather and sea were relatively calm, and the trawler continued en route to Nuuk, escorted by KNUD RASMUSSEN. On Tuesday February $23^{\text {rd }}$ the weather changed, and around 6 am KNUD RASMUSSEN informed the Danish Defence's Joint Arctic Command in Nuuk (JACO) that seven to eight meters high waves made it increasingly difficult to keep SAPUTI floating, and therefore, JACO decided to move the SAR helicopter from Kangerlussuaq to Nuuk. However, due to bad weather the helicopter was redirected to a helipad 150 kilometers north of Nuuk. One hour later, KNUD RASMUSSEN described the situation onboard SAPUTI as critical. The system, which had been devised to separate fish and water in the trawler's cargo room, broke down, and it was only a matter of time before the bilge pumps would break down. Therefore, it was decided to seal the cargo room, and allow it to be filled with seawater [41]. With the lower compartments of the trawler filled with water, SAPUTI's crew began to throw all unneeded and heavy equipment, for example, trawl doors, overboard, in order to stabilize the trawler, Also, the crew prepared for an evacuation. Four crews from SAPUTI were evacuated to KNUD RASMUSSEN by rigid-hulled inflatable boat (RHIB), but during the operation one of the RHIB's pontoons was punctured, and the RHIB could no longer be used, and due to the high waves KNUD RASMUSSEN's SAR vessel could not be deployed. Instead, JACO directed the SAR helicopter to the position of the two ships, in order to begin evacuation by hoist of the SAPUTI crew not involved in the navigation of the trawler. Yet, the SAR helicopter had to abandon its mission due to risk of ice accretion. Instead, a Canadian aircraft began to monitor the situation. SAPUTI and KNUD RASMUSSEN continued en route to Nuuk, at reduced speed, in order to minimize the risk for capsizing of the trawler. On Tuesday February $23^{\text {rd }}$ around 8 pm the two vessels arrived safely in the harbor of Nuuk. 
Not all actions initiated during the SAPUTI incident can be categorized as improvisation, as it is more appropriate to categorize a number of them as standard operation procedures during a SAR operation. However, when the technicians from KNUD RASMUSSEN devised a system to separate fish and water in the trawler's cargo room, and thereby quickly adapted the physical set-up in the trawler in an attempt to save the vessel before time ran out, as well as when the crew onboard SAPUTI began to throw unneeded equipment overboard, and thereby, dropped their tools [42], improvisation took place. In general, improvisation is a common phenomenon during SAR operations in the Arctic, and in the harsh Artic nature, the responders' ability to improvise ingenious solutions to unforeseen challenges may very well make the difference between success and failure. Consequently, it is important that organizational governance systems do not create structural conditions or limitations, which suppress improvisation. The design of exercises as well as the general organization of emergency preparedness plays a crucial role in training and allowing for, and even incentivizing such improvisation. One important lesson for emergency planners is accordingly to design exercises to place the responders in ambiguous situations that calls for improvisation. Furthermore, when organizing Arctic emergency response it seems more important to focus on securing the broadest possible expertise with all responders, rather than training and organizing more specialized and functionally differentiated emergency prepared units.

\subsection{Adaptation of Organization: Upscaling}

In cold contexts many emergencies concern searches for, or distress calls from, individual hunters and fishermen, and the local authorities manage these on an everyday basis using available resources and capabilities. For example, due to the limited rescue infrastructure in the Arctic, civilian ships, aircrafts and citizens who happen to be in the area often take part in SAR operations acting as "vessels of opportunity", a.k.a. "good Samaritans".

In the case of Greenland, the police and JACO hold much experience with the handling of day-today incidents like those mentioned above, but they typically find themselves stressed to the limit when they face large-scale incidents. In particular, the police and JACO are challenged by the limited social infrastructure, in the form of the limited availability of qualified personnel. Without reinforcements, the intense emergency work may quickly exhaust the personnel, and due to huge geographical distances it takes several days to organize and bring in outside assistance. Hence, it is essential to prepare organizations for fast upscaling in the case of large emergencies.

Upscaling can be intra- as well as inter-organizational. JACO, for example, is staffed to run a large emergency response for approximately 24 hours, and thus, for the emergency response to remain effective for a longer period, reinforcements must arrive within that time span. For this purpose, the Danish Defence has established the Arctic Response Force (ARF), which consists of a roster of personnel and equipment than can be mobilized and transported rapidly from Denmark to Greenland. When testing the ARF in 2016, during a major emergency exercise, JACO experienced that successful intra- 
organizational upscaling is not just about adding personnel, but also about speedy integration of the reinforcements into the ongoing emergency response. Speedy intra-organizational integration of reinforcements, however, is a complicated matter, as no two emergencies are alike; meaning that for every emergency a specific context emerges, and is continuously transformed [28, 30]. Hence, when brought in as reinforcements to an emergency responding organization, even trained and experienced emergency responders need time to get acquainted with the specific emergency context, and this must happen as the context continuously evolves. Essentially, they must become familiar with the prevailing answer to the "what's going on here?" question [43], while the answer, as well as its origins, evolve.

Another issue to be addressed is that due to the rareness of such large scale emergencies in the Arctic, the reinforcements bring a diversity of experiences from other kinds of emergencies with them to the upscaling organizations. For instance, they often bring different perceptions of what aspects of the emergency to focus on, what new information to pay attention to, etc., and this influences the updating of their understanding of the emergency [44]. In particular, the challenges associated with updating and maintaining a common situational picture in an emergency are magnified when the physical and social infrastructures are limited, when several authorities, both national and foreign, are involved, and when these institutions interact simultaneously. When this happens, a variation in emergency experiences, occupational routines, etc., enter the scene, and this may cause confusion and misunderstandings both within the upscaling organizations, and between them.

A final issue to be considered in relation to organizational upscaling during cold disasters is that it requires cooperation of multiple actors that not only differ in terms of mandate, experience, available resources, skills, and expertise, but often also in their respective professional culture(s). In the case of Greenland, civil-military relations and organizational cultures are crucial for understanding the challenges of responding to disasters, because essential formal responsibilities are distributed between different organization and institutions, such as the Government of Greenland, the Greenlandic Police and JACO. During a major emergency exercise in Greenland, the main players exhibited quite distinct organizational cultures. The governmental administration in Greenland, with its mixed Danish and Greenlandic staff, exhibited a bureaucratic culture preoccupied with developing and implementing regulations and policies, which required not only legal, but also academic expertise in a wide range of areas. The Danish-staffed JACO introduced a military culture in its camouflage-and-boots work uniform, its advanced and securitized communication equipment and availability of navy vessels, aircrafts and helicopters, as well as in its command structure and communication pervaded by NATO and military jargon. Finally, with its dominance of Greenlandic police officers, and the constant traffic in and out of the Nuuk police station, of Greenlandic citizens in need of the police's assistance and services, the Greenland Police signaled both public authority and social embeddedness in the civilian society. Inter-organizational cooperation is affected by diversities in organizational cultures, and although following one's own habitus may contribute to a sense of control and self-confidence, it may also pre- 
vent the inclusion of relevant inputs from others, and thereby, contribute to the "inaction" of others, and restrict the development of a shared understanding.

For the purpose of addressing the challenges related to updating and coordination of both local understandings and common situational pictures then emergency responders can take on an inquiring attitude $[45,46]$ immediately after joining their respective organizations, as thereby, they can familiarize themselves with the reasoning, which has resulted in the prevailing understandings and situational pictures. Introducing an inquiring practice can thus lead to faster intra-organizational integration of incoming reinforcements, as well as to better inter-organizational coordination during emergencies. Thereby, it can supplement the coordination, usually taking place at the strategic level of the emergency management system.

\subsection{Adaptation of Regulation: Negotiating}

A final kind of adaption is within the overall regulative framework for disaster response in the Arctic. As argued above, disaster responses in cold contexts often cuts across individual skills and habits, organizational capacity and existing cultures, however due to the complex geopolitical context it also often cuts through several legal jurisdictions. This means that in order to respond effectively to disasters in cold contexts, the involved organizations must be able to work around pre-existing jurisdictional limits and reach flexible arrangements beyond the predefined legal mandates of the organizations. Even within the jurisdiction of Greenland, this issue constantly arises due to the distinctive institutional arrangement with Denmark.

A crucial part of being able to orchestrate an effective and timely disaster response is a clear and thought-through pre-existing governance framework. Accordingly, we have in recent years witnessed a significant increase in disaster management regulation across the globe, on a national as well as regional level, dedicated to synchronize and prepare actors already before the disaster occurs $[47,48$, 49]. In the context of the European Union, significant resources have in recent years been invested in creating a cross-border coordination mechanism [50], as well as increasing synchronization and standardization of response frameworks and equipment.

Cold contexts lack behind in this field. Recently however, the Arctic Council has set out to improve the framework for cooperation in disaster situations between the many actors operating in the area. Two framework agreements have emerged in the last six years. The members of the Arctic Council have signed two agreements on respectively $\mathrm{SAR}^{7}$ and marine pollution. ${ }^{8}$ The aim of the agreements is to resolve some of the strategic noise around the major lines of governance; however, they still leave

\footnotetext{
7 The Arctic Council in 2011 made the Agreement on Cooperation on Aeronautical and Maritime SAR in the Arctic. The agreement most importantly divides the Arctic into zones in which the signatory parties have lead responsibility in SAR operations.

${ }^{8}$ Agreement on Cooperation on Marine Oil Pollution Preparedness and Response in the Arctic.
} 
major issues to be resolved either bilaterally or by the responders in the actual situation ${ }^{9}$. Accordingly, inter-jurisdictional adaptation and flexibility will remain crucial to the ability to respond effectively to cold disasters in the years to come.

In Greenland, several of the stakeholders involved in a recent emergency exercise, operated under different jurisdiction with different mandates. As pointed out above, such an institutional separation manifest itself immediately in different conflicting organizational cultures, but it also surface as real legal struggles over mandates and jurisdictions. Part of the setup of the exercise allowed for testing these mandates. The stakeholders had to deal with the evacuation of a ship carrying potentially dangerous materials. Already on day one of the exercise, strategic discussions took place between JACO and the Greenlandic Police on who should take lead, should the ship float into Greenlandic jurisdiction. The anticipation of this potential dilemma is an excellent example of the kind of negotiation necessary to govern disasters in a cold context, as it meant that the distribution of responsibility for the SAR part of the exercise did not become problematic. The negotiation, and thereby, the distribution of responsibility, is based on a formalized governance system, but it also relies on the cooperation and anticipation of the stakeholders operating at the strategic level. In concrete terms, this means that solutions to potential conflicts do not evolve through legal interpretation or argumentation, but rather through a kind of social negotiation, in which pre-established relations, trust and mutual respect are more important than the number of flown-in lawyers.

Accordingly, these situations are very context dependent, and highly contingent. In turn, a similar situation played out less favorably for the actors later on in the exercise. The issue of who should take charge of a potential oil spill within the three nautical mile demarcation remained, until very late, unsolved. This lack of regulative adaption on behalf of the actors caused significant problems. The lack of clarity on who ultimately held the responsibility for an oil pollution of such size and scale within the jurisdiction of the Government of Greenland, thereby took up a significant part of the work capacity of the governmental administration in Greenland, and ultimately, it was an obstacle for an effecttive response.

Setting up an effective disaster management system in a cold context, accordingly requires authorities to prepare along two separate trajectories. First, a trajectory not necessarily differentiating from warmer context, by clarifying as many gaps as possible before the disaster happens. A cold context, in particular, calls for such clarity, as ambiguity surrounding mandates or responsibility puts further pressure on the short window available for response. Second, central strategic actors should be trained in negotiating solutions to such gaps, in particular when these are left open by superseding political agendas (e.g. semi-permanent disputes over territory, independence or finances). Exercises should put specific emphasis on strategic level actors' abilities to find solutions, also to politically inopportune pro-

\footnotetext{
${ }^{9}$ For detailed analysis of the agreements and their value for Arctic Governance, see Lauta [51].
} 
blems, and thereby help to establish channels of communication and a common framework between the involved actors.

\section{Conclusion}

For the handsome sum of $\$ 22,500$, it is today possible to acquire a ticket with the Crystal Serenity cruise exploring the Northwest Passage, a voyage offering "unprecedented adventures and unsurpassed luxury". The webpage of Crystal further promises travelers, "unparalleled landscapes of grand glaciers, stunning fjords, and rare wildlife sightings as you learn the Arctic culture and its fascinating people”. Should Crystal Serenity ever collide with an iceberg in the Arctic - the rescue operation would take place in a cold and hostile environment; applying few or no available resources; and deal with significant uncertainty with regard to who should be responsible.

In this article, we claim that there is a need to consider the special features of disasters happening in cold contexts. Disasters and disaster management is not a one-size-fits-all, thus knowledge, expertise and experience from disasters in warmer, densely populated areas cannot blindly be transposed to disasters in cold contexts. We have argued that three particular features distinguish "cold disasters", from their warm relatives: (1) the time pressure is high, (2) there is no available infrastructure and (3) it is often unclear who is responsible for helping. With these three features in mind, we went on to argue that present disaster research's theoretical focus on vulnerability is directing our focus to structural solutions; but such solutions are hardly realistic in cold contexts. Rather, we suggest that cold disasters call for adaptation. On the individual level, the unforeseeable and harsh weather conditions put particular pressure on the ability of the emergency responders to improvise. On the intra-organizational level, the actors should be able to adapt the size of their organizations, and focus on building organizations able to do so. Finally, on the inter-jurisdictional or international level the actors are pushed to negotiate and adapt to fill the gaps left by the multiple actors and sets of regulation involved in any response. Accordingly, we identified three different forms of adaption, which are crucial for the organization and preparation of a cold context emergency organization: improve the conditions of improvisation; make the organizations scalable; and create flexible legal and political mechanisms. We do not claim that the three forms of adaption identified here are necessarily principally different from approaches already applied within the Nordic countries, but the extremity of the Arctic necessitate a higher degree of reliance upon such approaches. Hence, in the context of this special issue, the Arctic part of the Nordic countries adds another governance dimension to Nordic disaster management.

In turn, the main argument presented in this article is that the concepts and basic approaches commonly applied in disaster management cannot automatically be applied when dealing with cold disasters. In other words, there is an Arctic pivot to be considered when designing Nordic disaster management systems for the Arctic part of the Nordic countries. Rather than calling for further coherence, consistency and systematization of the disaster management system, this article points to the need for tailored governance strategies for a cold, in this case, Arctic context. Furthermore, the challenge of 
creating an effective disaster management structure for the Arctic is not only a matter of optimizing national strategies, it arguably also requires a higher degree of cross-border and cross-institutional cooperation than other national disasters.

These are simple messages, but easily forgotten when drafting comprehensive strategies in Copenhagen, Oslo, or Helsinki.

\section{Acknowledgements}

All the authors are affiliated with Copenhagen Center for Disaster Research (COPE), and acknowledge the financial support for this research received from Nordic Centre of Excellence on Resilience and Societal Security (NORDRESS). The authors thank the organizers of LIVEX'16 for allowing them to participate in the exercise as observers. In particular, we thank Bjørn Tegner Bay, Kim Jesper Jørgensen and the Government of Greenland for enabling us to conduct a comprehensive field study of the exercise. Morten Thanning Vendelø acknowledges the hospitality of University of Gothenburg, School of Business, Economics and Law, during the spring term 2017. Birgitte Refslund Sørensen and Kristian Cedervall Lauta acknowledge the University of Copenhagen 2016 excellence program for inter-disciplinary research project Changing Disasters.

\section{References}

[1] M. J. Zakour, D. F. Gillespie, Community Disaster Vulberability: Theory, Research, and Practice. Springer, New York, NY, 2013.

[2] D. Alexander, Our starting point, International Journal of Disaster Risk Reduction 1 (2012b) 1-4.

[3] S. G. Borgerson, The coming Arctic boom: as the ice melts, the region heats up, Foreign Affairs 92 (4) (2013) 76-V.

[4] G. Holland, The Arctic Ocean - the management of change in the northern seas, Ocean \& Coastal Management 45 (11-12) (2002) 841-851.

[5] M. W. Lore, Preventing disaster as the Arctic seas open for business, Sustainable Development Law \& Policy 8 (3) (2008) 36-37.

[6] D. Alexander, Models of social vulnerability to disasters, RCCS Annual Review 4 (2012a) 22-40.

[7] M. Bevir, A Theory of Governance, University of California Press, Berkeley, 2013.

[8] B. U. Hansen, Klima, in: B. H. Jakobsen, J. Böcher, N. Nielsen, R. Guttesen, O. Humlum \& E. Jensen (red.) Topografisk Atlas Grønland, C. A. Reitzels Forlag, København, 2000, pp. 26-29.

[9] T. Heleniak, D. Bogoyavlensky, Arctic populations and migration, in J. N. Larsen, G. Fondahl (eds.), Arctic Human Development Report: Regional Processes and Global Linkages, Nordic Council of Ministers, Copenhagen, 2015, pp. 53-104.

[10] L. Pedersen, Grønlands befolkning 2017, Statistics Greenland, 2017, http://www.stat.gl/publ/da/BE/201701/pdf/Grønlands\%20befolkning\%202017.pdf (accessed 17.09.11) 
[11] B. Vahl, N. Kleemann, Greenland in Figures 2015, Statistics Greenland, Nuuk, 2015.

[12] J. O. P. Pedersen, Satellitter og Droner i Arktis - Multiuse af en Rumbaseret Infrastruktur, DTU Space - Institut for Rumforskning- og teknologi, Lyngby, 2016.

[13] M. Fuglede, J. Kidmose, M. Lanteigne, G. Schaub Jr., Kina, Grønland, Danmark - konsekvenser og muligheder i kinesisk Arktispolitik, Center for Militære Studier, København, 2014.

[14] C. Jex, Denmark's cold war struggle for scientific control of Greenland, Science Nordic, January $29^{\text {th }}$ http://sciencenordic.com/denmark\%E2\%80\%99s-cold-war-struggle-scientific-controlgreenland, 2017 (accessed 17.02.22)

[15] J. Dittmer, S. Moisio, A. Ingram, K. Dodds, Have you heard the one about the disappearing ice? recasting Arctic geopolitics, Political Geography 30 (4) (2011) 202-214.

[16] C. M. Perry, B. Andersen, New Dynamics in the Arctic Region: Implications for National Security and International Collaboration, CreateSpace Independent Publishing Platform, 2012.

[17] T. B. Arlov. A short history of Svalbard. Oslo: Norwegian Polar Institute (1994) 80.

[18] Ø, Østerrud, G. Hønneland, Geopolitics and international governance in the Arctic, Arctic Review on Law and Politics 5 (2) (2014) 156-176.

[19] K.S. Kristensen, J. Rahbek-Clemmensen, Greenland and the International Politics of a Changing Arctic Postcolonial Paradiplomacy between High and Low Politics, Routledge (2018).

[20] O. Young, Arctic tipping points: governance in turbulent times, Ambio 41 (1) (2012) 75-84.

[21] D. Alexander, Our starting point, International Journal of Disaster Risk Reduction 1 (2012b) 1-4

[22] M. J. Zakour, D. F. Gillespie, Community Disaster Vulberability: Theory, Research, and Practice. Springer, New York, NY, 2013.

[23] J. Weichselgartner, Disaster mitigation: The concept of vulnerability revisited, Disaster Prevention and Management 10 (2) (2001) 85-94.

[24] D. A. McEntire, Development, disasters, and vulnerability: A discussion of divergent theories and the need for their integration, Disaster Prevention and Management 13 (3) (2004) 193-198.

[25] P. Blaikie, T. Cannon, I. Davis, B. Wisner, At Risk, Natural Hazards, People's Vulnerablity and Disaaters. Routledge, London, 1994.

[26] B. Wisner, P. Blaikie, T. Cannon, I. Davis, At Risk, Natural Hazards, People's Vulnerability and Disasters. Second Edition. Routledge, London, 2003.

[27] C. Perrow, Normal Accidents - Living with High-Risk Technologies, Princeton University Press, Princeton, 1984.

[28] M. Augier, S. Z. Shariq, M. T. Vendelø, Understanding context: its emergence, transformation and role in tacit knowledge sharing, Journal of Knowledge Management 5 (2) (2001) 125-136.

[29] C. Rerup, "Houston, we have a problem": anticipation and improvisation as sources of organizational resilience, Comportamento Organizacional E Gestão 7 (1) (2001) 27-44. 
[30] S. Z. Shariq, M. T. Vendelø, Contexts for tacit knowledge sharing, in: D. G. Schwartz, D. Te'eni (eds.), Encyclopedia of Knowledge Management, second edition, Information Science Reference, Hershey, PA, 2011, pp. 121-130.

[31] E.C. Alozie, The 2010 Chilean Mining Accident: The Triumph of Transparency and Calm Leadership, in: A.M. George, C.B. Pratt, Case Studies in Crisis Communication: International Perspectives on Hits and Misses, Routledge, Abingdon, 2012.

[32] R. Axelrod, M. D. Cohen, Harnessing Complexity: Organizational Implications of a Scientific Frontier, The Free Press, New York, NY, 1999.

[33] J. G. March, R. Weissinger-Baylon (eds.), Ambiguity and Command: Organizational Perspectives on Military Decision Making, Pitman, Marshfield, MA, 1986.

[34] D. Pietri, A. B. Soule IV, J. Kershner, P. Soles, M. Sullivan, The Arctic shipping and environmental management agreement: a regime for marine pollution, Coastal Management 36 (5) (2008) 508-523.

[35] C. Moorman, A. Miner, Organizational improvisation and organizational memory, Academy of Management Review 23 (4) (1998) 698-723.

[36] C. U. Ciborra, Notes on improvisation and time in organizations, Accounting, Management and Information Technology 9 (1) (1999) 77-94.

[37] M. T. Vendel $\varnothing$, Improvisation and learning in organizations - an opportunity for future empirical research, Management Learning 40 (4) (2009) 449-456.

[38] S. Leybourne, G. Lynn, M. T. Vendelø, Forms, metaphors and themes: an introduction to the special issue on organizational improvisation, Creativity \& Innovation Management 23 (4) (2014) 353-358.

[39] K. H. Roberts, R. Bea, Must accidents happen? lessons from high-reliability organizations, Academy of Management Executive 15 (3) (2001) 70-78.

[40] J. Elkjær, Vellykket assistance til canadisk trawler (Successful assistance to Canadian trawler). Forsvaret.dk, http://www2.forsvaret.dk/omos/organisation/arktisk/nyhederfraAK/Pages/Assistancetilcanadiskt rawler.aspx, 2016 (accessed 17.01.27)

[41] Nuuk TV, Redningsaktion for den canadiske trawler Saputi (Rescue Operation for the Canadian trawler Saputi), February 24 ${ }^{\text {th }}$, http://www.nuuktv.gl/nyhed/saputi-sar/, 2016 (Accessed 17.02.27)

[42] K. E. Weick, The collapse of sensemaking in organizations: the Mann Gulch disaster, Administrative Science Quarterly 38 (4) (1993) 628-652.

[43] K. E. Weick, K. M. Sutcliffe, D. Obstfeld, Organizing and the process of sensemaking, Organization Science 16 (4) (2005) 409-21.

[44] M. K. Christianson, Updating as Part of Everyday Work: An Interactional Perspective, Ph.D. dissertation, University of Michigan, 2009. 
[45] J. F. Courtney, J. D. Haynes, D. B. Paradice (eds.), Inquiring Organizations: Moving from Knowledge Management to Wisdom, Idea Group Publishing, Hershey, PA, 2005.

[46] M.T. Vendelø, I. Constantiou, Varying Interpretations of Technology as a Problem in Markets for Customised High-Tech products: Towards an Inquiring Dialogue Approach. International Journal of technology Management 59 (1) (2012) 45-62..

[47] D. Fisher, Law and Legal Issues in International Disaster Response: A Desk Study, International Federation of Red Cross and Red Crescent Societies, Geneva, 2007.

[48] A. de Guttry, M. Gestri, G. Venturini (eds.), International Disaster Response Law, Springer, The Hague, 2012.

[49] A. Lópex-Carresi, M. Fordham, B. Wisner, I. Kelman J. Gaillard, Disaster Management: International Lessons in Risk Reduction, Response and Recovery, Routledge, London, 2014.

[50] A. Boin, M. Ekengren, M. Rhinard, The European Union as Crisis Manager: Patterns and Prospects, Cambridge University Press, Cambridge, 2013.

[51] K. C. Lauta, A drop in the ocean - marine oil pollution preparedness and response in the Arctic, Arctic Review on Law and Politics, 5 (2) (2014) 227-249. 